\title{
A Replicated Assessment of THE CRITICAL SUCCESS FACTORS For THE ADOPTION OF MOBILE GOVERnMENT SERVICES: THE CASE OF JORDAN
}

\author{
Yousef Elsheikh and Mohammad Hijjawi
}

Department of Computer Science, Applied Science University, Amman, Jordan

\begin{abstract}
Previous research indicates that there is a failure in the adoption of e-government services to citizens as planned in the context of developing countries. Obstacles behind this failure are varied, including sociocultural, economic and technical obstacles. But with recent advances in mobile technologies as well as the pervasive penetration of mobile phones, governments in developing countries including Jordan have been able to overcome most of these obstacles through the so-called mobile government (or m-government). This has provided an alternative channel for governments to improve the interaction with their citizens, as well as the quality of services provided to them. Accordingly, the exploration of the factors that affect the adoption of m-government services would reduce the gap between government strategies and policies relating to the development of m-government services on the one hand, and the perceptions of citizens on the other hand, allowing for a better understanding of citizens' needs and priorities that must be taken into account by the governments in order to ensure the success of such services on a large scale. This research is based on a re-evaluation of the empirical results of a comprehensive study conducted by Susanto and Goodwin (2010), which concludes that there are fifteen factors that are likely to affect citizens in 25 countries around the world to adopt SMS-based e-government services, but in the context of a different country in the Arab world, namely Jordan.
\end{abstract}

\section{KEYWORDS}

Mobile-Government, Electronic-Government, SMS Technology, Developing Countries, Jordan

\section{INTRODUCTION}

In recent years, the world has started to witness changes in key aspects of life. Among those aspects highlights the widespread use of mobile technologies in governments [1,2]. This means that governments have started looking for technological alternatives to enable and improve interaction with their stakeholders such as citizens, businesses or government entities and thus provide better public services. This has been through mobile or wireless technologies using devices such as cell phones, laptops, or PDAs with wireless Internet access, where it is believed that these technologies would make access to public services easier on the one hand, on the other hand it is a new way to build trust with stakeholders to those governments [2]. Mobile government (or m-government) is simply accessing government information and services via the Internet using portable devices such as mobile phones, laptops, or PDAs [2, 4]. On a global scale, governments are experiencing high competition among themselves regarding the development and adoption of public services to citizens via the Internet on the one hand and on the other hand 
seeks to reconsider the use of mobile wireless technologies in order to gain new competitive advantages $[1,2,3]$.

Hence, the reduction of operational costs and physical infrastructure [2], increase the internal efficiency of the government [12], gain the loyalty and satisfaction of stakeholders [11], and most importantly, improve the quality of public services [9], all of these among the main advantages of e-government services that are delivered via mobile devices. These services may also have enabled governments around the world to serve, as well as to reach faster and on time to a greater number of stakeholders (citizens and others) without any additional cost, or in most cases, the cost may be neglected, since the penetration of mobile devices has become higher than the Internet penetration in most developed and developing countries [4, 7, 9, 15]. For many citizens, there are other factors of importance to them, which are summarized in the adoption of services on a high level of flexibility, convenience, timeliness, as well as personalization [16, 17]. However, some studies have also found that building trust with governments and citizens' expectations are among the factors that may affect the citizens to deliver e-government services through mobile devices [17]. This since citizens want to make sure that their personal data are processed securely through such services, as well as that the data cannot be accessed or stolen by those who are not authorized [17].

On the other hand, some studies addressed the factors that are likely to affect the adoption of egovernment services through mobile devices in different contexts, and found considerable variation in the adoption rates of these services. For example, in the UAE, the adoption rate of $\mathrm{m}$ government services is $89 \%$ of mobile Internet users, while the rate for both the UK and the US is $61 \%$ and $57 \%$, respectively, and Germany is only $47 \%$ [18]. Thus, a comprehensive study to explore the determinants of adoption of m-government services is essential since its features are unique and significantly different compared with traditional governments [19]. In Jordan, despite the fact that the high rate of Internet penetration compared to some neighboring countries, the rate of adoption of m-government services is still low, see Table 1 for some common m-government services provided in Jordan [35]. However, the reason behind this, a number of relevant factors such as privacy and security, quality of services, m-government features, trust, public awareness, infrastructural constraints, cost, legal and marketing concerns [3,7,8,16,21,22,23,24,25,26,27,28]. Thus, assessing the factors that are likely to influence the adoption of m-government services in Jordan is important since the result will be of benefit to government institutions there and in countries with similar circumstances to understand the needs and requirements of citizens, increase participation and develop strategies accordingly, leading to an increase in the adoption of m-government services [25, 29]. 
Table 1: Common m-government services in the Jordanian public sector

\begin{tabular}{|l|l|l|}
\hline Ministry or department & Service Name & Service Code \\
\hline Greater Amman & 1 vehicles irregularities & 41 \\
Municipality & 2 complaints & 42 \\
& 3Tax of buildings \& lands & 43 \\
& 4 bidding & 44 \\
& 5 professions license Information & 45 \\
\hline Jordan Customs & Inquire about the car customs & 31 \\
& Balances temporary entry / customs & 32 \\
& Member ID / Customs & 33 \\
& Guarantees transit / Customs & 34 \\
\hline Civil Service Bureau & Case custom transaction & 36 \\
\hline Royal Jordanian & Competitive ranking: Provided by sending the number of the service & 71 \\
& and the Social Number of the citizen and he will get his ranking & \\
\hline & Royal flights arrival & 231 \\
& flights depart Royal & 232 \\
\hline
\end{tabular}

Since studies on m-government services in Jordan are limited [30,31], this research is looking at the critical success factors that affect the adoption of m-government services such as perceived ease of use, perceived usefulness, perceived responsiveness to service, perceived efficiency in time and distance, perceived convenience, perceived trust in the SMS technology, perceived value for money, perceived relevance, quality and reliability of the information, perceived compatibility, self-efficacy in using SMS, perceived reliability of mobile network and system performance, perceived risk to user privacy, trust of the government and perceived quality of public services, perceived risk to money, perceived availability of device and infrastructure in the context of Jordan [13]. [3,7,28,32] also pointed out that previous studies on m-government services are still inconclusive, including Jordan, and therefore there is a need for further evidence to confirm the main determinants of the adoption of m-government services. Accordingly, the results of this research contribute to providing a greater understanding of the critical success factors for m-government services to fill the gap in the current body of literature, particularly in the context of developing countries.

\section{LITERATURE REVIEW}

Mobile communication technologies are a good option for many to interact with their governments all over the world for various reasons, including convenient, quick and low-cost access to public information and services at any time, any place [31]. However, the digital divide as well as Internet connection fee are among the challenges facing the successful implementation of e-government initiatives in developing countries, including Jordan [30]. To overcome these challenges, some of those governments have resorted to encourage the use of m-government services creating opportunities to cut costs, leading to greater participation on the one hand and reduce the time and effort to communicate with the public on the other hand [2]. Jordan's Telecommunication Regulatory Commission (TRC) statistics for the second quarter of the year 2015 revealed that $95 \%$ of Jordanians have mobile phones, compared with $88 \%$ in Egypt and $86 \%$ in Lebanon. This means that mobile phones offer an alternative channel to governments, including the Jordanian government to communicate with the public through the use of SMSbased services, thus faster, easier access to information regardless of time and place. 
A study of [33] argues the two types of SMS-based services; pull and push SMS services. Push SMS services are used by government departments to send alerts and notifications related to various public services to citizens, while the pull SMS services are used by citizens to get some information about the various public services, by receiving a message with the requested information from the concerned government department. Jordanian government figures showed that the number of mobile phone subscribers exceeded the number of the population by up to $152 \%$ (12.3 million active mobile subscribers) at the end of June of the year 2015, compared with $147 \%$ at the end of last June of the year 2014, where the total number of active mobile subscribers reached 11.1 million. According to the International Telecommunication Union (ITU), Jordan has recently been rated as the second most active market for mobile phones in the Arab region on the one hand, and among the lowest in terms of mobile subscription on the other hand, in a study by the Arab Advisers Group, which was issued in July of the year 2015 . According to the Department of Statistics survey data, $98.1 \%$ of Jordanian households have mobile phones, $70 \%$ of them have smart phones. The use of m-government provides an alternative, flexible and easy to use to gain access to public services by the citizens, especially women, the disabled and those living in rural and remote areas that find it difficult to access to public services using traditional methods or do not have access to the Internet. This would save time and effort for them, as well as the reduction of bureaucratic processes. Few studies have addressed those factors that can positively or negatively affect the adoption of mobile technology, especially the SMS in the provision of government services and information. Among these studies, a study of [13], which showed that despite the adoption of SMS for communication between the Filipinos, the government sector is still unable to gain trust by the public to interact with the services provided via SMS, where low response rate of transactions, as well as poor back-office management, both of which stand as a barrier preventing the acceptance of such services. Another study of [13] showed that the cost of the SMS is among the determinants that affect public acceptance of government services provided via SMS in Denmark and Sweden. Privacy also was among the determinants of public acceptance or non-acceptance of the use of government services provided through SMS [11]. [6] also concluded that the willingness of the Saudis to use mobile devices to get government information and services associated with two key factors: First, the perception of the benefits of mobile devices as it facilitates access to information and government services anytime anywhere, secondly, to ensure a high level of security and privacy during the exchange of information via mobile devices. In another study in the same context, [19] concluded that the success of mobile government services associated with providing a robust IT infrastructure, as well as ensure the security, privacy and trust in mobile services. [3] Concluded, through a qualitative study in Jordan, the five factors that will influence the use of e-government services provided through SMS. These factors are public Awareness, lack of trust, where the vast majority of citizens have growing concerns about privacy, security and misuse of personal information when the information is exchanged over the Internet, service cost, limited IT infrastructure, and finally the lack of a legal framework that protects citizens through the exchange of information. [31] also concluded in the same context that the failure to visualize the benefits of mobile government services, would adversely affect the rate of acceptance of the citizens for such services. [16] presented the results of an online survey carried out by a group of Indian experts on the factors influencing the use of m-government services in their country. These factors were summarized as follows: the need for a government strategy to adopt these services, ensure access to those services, increase awareness of the benefits of those services and finally ensure the quality of m-government services. [26] concluded that the adoption of m-government services in China's rural areas, depends directly and indirectly on the following factors: perception of ease of use, perceived benefits in the short and long term, 
integrity, benevolence, image and social influence, all of these have a significant and positive impact on the intention to use m-government services. Specifically, the perception of ease of use, long-term benefits and social influence, all of which have a direct impact on the intention to use, while the perception of short-term benefits, integrity, benevolence and the image, all of these have an indirect impact. Other studies, such as [27], presented the positive role of the mass media in promoting government services provided through SMS in Nigeria to enable the citizens there to use those services. [28] also concluded,through a quantitative study in Egypt, that the adoption of e-government services via mobile devices is influenced by the following factors: Perception of $\mathrm{m}$-service usefulness, its compatibility with lifestyle, awareness, social influence and finally direct interaction with the government (face to face). Because of the complex nature of the determinants of adoption and use of existing mobile-based technologies in governments, researchers have been placed in front of an urgent need to carry out a comprehensive study includes not only the determinants of the supply-side for the deployment of those services, but also the determinants of the demand-side in different contexts. Yet, most of the research has dealt with either the supply-side, or the demand-side of the determinants and not both to ensure the success of e-government services provided through mobile devices. This research fills that gap, and addresses the factors that affect the success of the adoption and use of m-government services by employing a holistic approach [13] that uses multiple perspectives.

\section{RESEARCH MODEL AND HYPOTHESES}

This research aims to study the factors that will affect the adoption of e-government services provided through mobile devices in Jordan. Specifically, this research seeks to re-examine the relationship and the influence of some of the factors previously identified in the study [13] on the adoption of m-government services in the context of an Arab country, namely Jordan, as shown in Figure 1 below and the following hypotheses:

H1: Perceived ease of use (PEO) is found to be a key factor affecting the citizens to adopt mgovernment services.

$\mathrm{H} 2$ : Perceived efficiency in time as well as distance (PETD) is found to be a key factor affecting the citizens to adopt m-government services.

H3: Perceived service value for money (PSVM) is found to be a key factor affecting the citizens to adopt m-government services.

H4: Perceived responsiveness to service (PR) is found to be a key factor affecting the citizens to adopt m-government services.

H5: Perceived usefulness (PU) is found to be a key factor affecting the citizens to adopt $\mathrm{m}$ government services.

H6: Perceived convenience (PC) is found to be a key factor affecting the citizens to adopt $\mathrm{m}$ government services.

H7: Perceived trust in SMS technology (PTT) is found to be a key factor affecting the citizens to adopt m-government services. 
H8: Perceived relevance, quality and reliability (PRQR) of the information is found to be a key factor affecting the citizens to adopt m-government services.

H9: Perceived risk to user privacy (PRV) is found to be a key factor affecting the citizens to adopt m-government services.

H10: Perceived reliability of mobile network (PRNT) and system performance is found to be a key factor affecting the citizens to adopt m-government services.

H11: Perceived quality of public services (PQOS) is found to be a key factor affecting the citizens to adopt m-government services.

H12: Perceived risk to money (PRM) is found to be a key factor affecting the citizens to adopt mgovernment services.

H13: Perceived availability of device and infrastructure (PINF) is found to be a key factor affecting the citizens to adopt m-government services.

H14: Perceived compatibility (PCOMP) is found to be a key factor affecting the citizens to adopt m-government services.

H15: Perceived self-efficacy in using SMS technology (PSE) is found to be a key factor affecting the citizens to adopt m-government services.

\section{Methodology}

In this research, one dependent variable along with fifteen independent variables will be tested. The dependent variable is the decision for the adoption of $\mathrm{m}$-government services while the independent variables are shown in the hypotheses above, and Figure 1 below

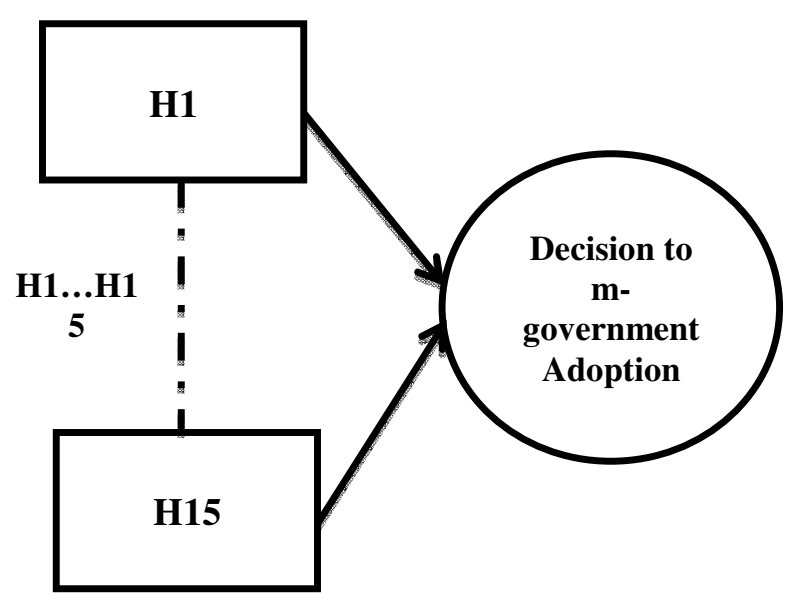

Figure 1: Research Model 


\subsection{RESEARCH INSTRUMENT}

In this research, two types of data were used; primary data and secondary data. Secondary data was obtained through articles published in both e-journals, local and international conferences related to the research area. For primary data, a questionnaire was designed to collect data, which included two parts: Part A contains demographic information for respondents, which consists of age, gender, position and knowledge in the use of mobile phones and m-government services. Section B, measures the independent and dependent variables through which was adopted in [13], but with some changes depending on the context under investigation. Each variable was measured by 5 point Likert scale from 1 (Strongly Disagree) to 5 (Strongly Agree).

\subsection{SAMPLING}

300 survey questionnaires were distributed randomly to students, administrators and academics from major Jordanian universities. 31 of those were incomplete and therefore were excluded from any further analysis in this research. Accordingly, 269 questionnaires were finalized for analysis.

\subsection{DAta AnALYSIS}

In this research, the Statistical Package for Social Sciences (SPSS) software version 20 was used to test hypotheses.

\section{RESULTS AND DISCUSSION}

A sample of 269 respondents was used to analyze the data and test hypotheses. Of the sample, 182 were male respondents $(68 \%)$, while female respondents $(32 \%)$. More than half of the respondents were students (54\%), who ranged in age between 18 and $22(78 \%)$. The rest of the respondents were of the non-academic staff (18\%) and academic staff (28\%). The highest percentage of respondents was from mobile phone users $(88 \%)$. More importantly, most of the respondents were of those who have knowledge of m-government services, but not from the users of those services. This would reflect the exact factors for not adopting this type of service by the respondents under investigation (66\%). Table 2 below shows the background characteristics of respondents.

Table 2: Background characteristics of respondents

\begin{tabular}{|l|l|l|l|}
\hline Variable & Category & Frequency & Percentage \\
\hline \multirow{5}{*}{ Position } & Student & 145 & $54 \%$ \\
\cline { 2 - 4 } & Non-academic staff & 48 & $18 \%$ \\
\cline { 2 - 4 } & Academic staff & 76 & $28 \%$ \\
\hline Variable & Category & Frequency & Percentage \\
\hline \multirow{3}{*}{ Age } & $18-22$ & 209 & $78 \%$ \\
\cline { 2 - 4 } & $23-27$ & 32 & $12 \%$ \\
\cline { 2 - 4 } & Above 27 & 28 & $10 \%$ \\
\hline Variable & Category & Frequency & Percentage \\
\hline Gender & Male & 182 & $68 \%$ \\
\cline { 2 - 4 } & Female & 87 & $32 \%$ \\
\hline
\end{tabular}


International Journal of Computer Science \& Information Technology (IJCSIT) Vol 8, No 4, August 2016

\begin{tabular}{|l|l|l|l|}
\hline Variable & Category & Frequency & Percentage \\
\hline \multirow{2}{*}{$\begin{array}{l}\text { Knowledge in the use } \\
\text { of mobile phones }\end{array}$} & Excellent & 236 & $88 \%$ \\
\cline { 2 - 4 } & Average & 26 & $10 \%$ \\
\cline { 2 - 4 } & Poor & 7 & $2 \%$ \\
\hline Variable & Category & Frequency & Percentage \\
\hline \multirow{2}{*}{$\begin{array}{l}\text { Knowledge in the use } \\
\text { of m-government } \\
\text { services }\end{array}$} & Knowledge\& use & 16 & $6 \%$ \\
\cline { 2 - 4 } & Know \& do not use & 177 & $66 \%$ \\
\cline { 2 - 4 } & $\begin{array}{l}\text { Lack of knowledge and } \\
\text { use }\end{array}$ & 76 & $28 \%$ \\
\hline
\end{tabular}

Of all the variables, perceived risk to user privacy (PRV) was ranked first in terms of the highest mean (4.82), while the lowest mean in the rank was for the perceived ease of use (PEO) (3.55). All Means were higher than 3.5 and therefore normally distributed on the basis of normality test in Table 3.

Reliability Analysis was applied to test the internal consistency of the research variables. Results showed that the Cronbach $\alpha$ values were quite high for all the variables; $\alpha$ values obtained were more than 0.7 [34], as shown in Table 3. The highest $\alpha$ value was for the m-government adoption (MGOV) (0.924), while the lowest $\alpha$ value was for the perceived self-efficacy in using SMS technology (PSE) (0.706). Pearson Correlation Analysis (PC) was also applied to test research hypotheses H1 to H15. Perceived risk to user privacy (PRV) has the highest association on user adoption of m-government services, in reference to a very strong correlation level (Correlation Coefficient $\mathrm{r}=0.885$ ); followed by the perceived trust in SMS technology (PTT) (Correlation Coefficient $\mathrm{r}=0.7$ ), which has a strong correlation level; perceived efficiency in time as well as distance (PETD) (Correlation Coefficient of 0.687) has a strong correlation level; perceived ease of use (PEO) (Correlation Coefficient of 0.511) has a moderate correlation level; perceived service value for money (PSVM) (Correlation Coefficient of 0.408) has a moderate correlation level; perceived reliability of mobile network (PRNT) and system performance (Correlation Coefficient of 0.392) has a weak correlation level; perceived availability of device and infrastructure (PINF) (Correlation Coefficient of 0.289) has a weak correlation level, and finally, each of the following has no association on user adoption of m-government services, in reference to a very weak correlation level, such as perceived responsiveness to service (PR) (Correlation Coefficient of 0.004), perceived usefulness (PU) (Correlation Coefficient of 0.032), perceived convenience (PC) (Correlation Coefficient of 0.009), perceived relevance, quality and reliability of the information (PRQR) (Correlation Coefficient of 0.019), perceived quality of public services (PQOS) (Correlation Coefficient of 0.001), perceived risk to money (PRM) (Correlation Coefficient of 0.048), perceived compatibility (PCOMP) (Correlation Coefficient of 0.003), and perceived self-efficacy in using SMS technology (PSE) (Correlation Coefficient of 0.007). 
International Journal of Computer Science \& Information Technology (IJCSIT) Vol 8, No 4, August 2016

Table 3: Descriptive statistics

\begin{tabular}{|c|c|c|c|c|c|c|c|c|c|}
\hline $\begin{array}{c}\text { Resear } \\
\text { ch } \\
\text { Variab } \\
\text { le }\end{array}$ & $\begin{array}{c}\text { Valid } \\
\text { Mis }\end{array}$ & $\begin{array}{c}\mathbf{N} \\
\text { sing }\end{array}$ & $\begin{array}{c}\text { Skewn } \\
\text { ess } \\
\text { Statisti } \\
\text { c }\end{array}$ & $\begin{array}{c}\text { Standa } \\
\text { rd } \\
\text { Error }\end{array}$ & $\begin{array}{c}\text { Kurtos } \\
\text { is } \\
\text { Statisti } \\
\mathbf{c}\end{array}$ & $\begin{array}{c}\text { Standar } \\
\text { d Error }\end{array}$ & $\begin{array}{c}\text { Mea } \\
\mathbf{n}\end{array}$ & $\begin{array}{c}\text { Standard } \\
\text { Deviation }\end{array}$ & $\begin{array}{c}\text { Cron } \\
\text { bach } \\
\text { Alpha } \\
\text { (CA) }\end{array}$ \\
\hline PEO & 269 & 0 & -1.464 & 0.107 & 2.866 & 0.213 & 3.55 & 0.459 & 0.812 \\
\hline PETD & 269 & 0 & -0.234 & 0.107 & 0.451 & 0.213 & 4.19 & 0.784 & 0.831 \\
\hline PSVM & 269 & 0 & -0.583 & 0.107 & 0.374 & 0.213 & 4.66 & 1.055 & 0.91 \\
\hline PR & 269 & 0 & -0.394 & 0.107 & 1.082 & 0.213 & 4.25 & 0.576 & 0.713 \\
\hline PU & 269 & 0 & -0.289 & 0.107 & 0.258 & 0.213 & 4.21 & 0.651 & 0.821 \\
\hline PC & 269 & 0 & -0.23 & 0.107 & 0.705 & 0.213 & 3.71 & 0.737 & 0.884 \\
\hline PTT & 269 & 0 & -1.266 & 0.107 & 1.73 & 0.213 & 3.85 & 0.765 & 0.761 \\
\hline PRQR & 269 & 0 & -0.269 & 0.107 & 0.475 & 0.213 & 3.88 & 0.833 & 0.745 \\
\hline PRV & 269 & 0 & -1.94 & 0.107 & 1.77 & 0.213 & 4.82 & 0.727 & 0.842 \\
\hline PRNT & 269 & 0 & -0.789 & 0.107 & 0.68 & 0.213 & 4.5 & 0.794 & 0.773 \\
\hline PQOS & 269 & 0 & -1.289 & 0.107 & 3.005 & 0.213 & 3.67 & 0.583 & 0.855 \\
\hline PRM & 269 & 0 & -0.862 & 0.107 & 0.246 & 0.213 & 4.33 & 0.725 & 0.707 \\
\hline PINF & 269 & 0 & -0.906 & 0.107 & 1.862 & 0.213 & 3.57 & 0.803 & 0.818 \\
\hline PCOM & 269 & 0 & -0.45 & 0.107 & 0.559 & 0.213 & 3.95 & 0.821 & 0.782 \\
\hline P & & & & & & & & & \\
\hline PSE & 269 & 0 & -0.838 & 0.107 & 0.6 & 0.213 & 3.78 & 0.762 & 0.706 \\
\hline MGOV & 269 & 0 & -0.9 & 0.107 & 1.998 & 0.213 & 4.20 & 0.824 & 0.924 \\
\hline
\end{tabular}

Table 4: Pearson correlation coefficients between research variables and adoption of m-government services $(* *=$ significance at the 0.001 level)

\begin{tabular}{|c|c|c|c|}
\hline Hypothesis & $\begin{array}{c}\text { Correlation } \\
\text { Coefficient (r) } \\
\end{array}$ & Correlation Level & Hypothesis Support \\
\hline $\mathrm{H} 1$ & $0.511 * *$ & Moderate & Yes (accepted) \\
\hline $\mathrm{H} 2$ & $0.687 * *$ & Strong & Yes (accepted) \\
\hline $\mathrm{H} 3$ & $0.408 * *$ & Moderate & Yes (accepted) \\
\hline $\mathrm{H} 4$ & $0.004 * *$ & Very Weak & No (rejected) \\
\hline $\mathrm{H} 5$ & $0.032 * *$ & Very Weak & No (rejected) \\
\hline H6 & $0.009 * *$ & Very Weak & No (rejected) \\
\hline $\mathrm{H} 7$ & $0.7 * *$ & Strong & Yes (accepted) \\
\hline $\mathrm{H} 8$ & $0.019 * *$ & Very Weak & No (rejected) \\
\hline H9 & $0.885 * *$ & Very Strong & Yes (accepted) \\
\hline $\mathrm{H} 10$ & $0.392 * *$ & Weak & Yes (accepted) \\
\hline H11 & $0.001 * *$ & Very Weak & No (rejected) \\
\hline H12 & $0.048 * *$ & Very Weak & No (rejected) \\
\hline H13 & $0.289 * *$ & Weak & Yes (accepted) \\
\hline $\mathrm{H} 14$ & $0.003 * *$ & Very Weak & No (rejected) \\
\hline $\mathrm{H} 15$ & $0.007 * *$ & Very Weak & No (rejected) \\
\hline
\end{tabular}

Findings of this research are consistent to a large extent with other research findings conducted in the same context $[3,30,31,32]$. Further, Multiple Linear Regression (MLR) Analysis was applied 
to test and predict the impact of the fifteen independent variables on the adoption of $\mathrm{m}$ government services. Table 4 shows the result of applying the MLR. Figure 2 below shows a summary of the factors with a positive impact on the decision to adopt m-government services in the context under investigation.

Table 5: Multiple linear regression model summary $(* * *=$ significance at $\mathrm{p}<0.001, * *=$ significance at $\mathrm{p}<0.01$ and $*=$ significance at $\mathrm{p}<0.05$ level)

\begin{tabular}{|c|c|c|c|}
\hline Model & $\begin{array}{c}\text { Standardized } \\
\text { Coefficient Beta } \\
(\boldsymbol{\beta})\end{array}$ & t & Sig \\
\hline Constant & & -1.355 & 0.18 \\
\hline PEO & 0.521 & 2.001 & $* * *$ \\
\hline PETD & 0.402 & 2.873 & $* * *$ \\
\hline PSVM & 0.333 & 3.037 & 0.71 \\
\hline PR & 0.078 & 0.126 & 0.55 \\
\hline PU & 0.013 & 1.605 & 0.26 \\
\hline PC & 0.007 & 1.105 & $* * *$ \\
\hline PTT & 0.239 & 4.478 & 0.44 \\
\hline PRQR & 0.017 & 1.872 & $* * *$ \\
\hline PRV & 0.689 & 2.356 & 0.19 \\
\hline PRNT & 0.499 & 2.081 & 0.77 \\
\hline PQOS & 0.056 & 0.417 & $*$ \\
\hline PRM & 0.099 & 1.231 & 0.96 \\
\hline PINF & 0.546 & 4.017 & 0.22 \\
\hline PCOMP & 0.032 & 0.596 & 1.773 \\
\hline PSE & 0.029 & & \\
\hline
\end{tabular}

As a result of the MLR Analysis, The adjusted R square showed 0.67, which means that nearly $67 \%$ of the variation in the adoption of m-government can be explained through the variables that were analyzed in this research. ANOVA was also applied and showed a good model fit with the collected data (F-statistics $=78.62$ and $p$-value $<0.001)$. Most of the variables that were analyzed in Table 5 contributed significantly to the prediction of citizen adoption for $\mathrm{m}$-government services at $p<0.001$ significance level, with the exception of two variables; perception of efficiency in time as well as distance at $\mathrm{p}<0.01$ significance level as well as the perception of the availability of device and infrastructure at $\mathrm{p}<0.05$ significance level. In other words, the results of the statistical analysis contained in the last two Tables 3 and 4, contributed significantly to test hypotheses formulated above in terms of its acceptance or rejection. 


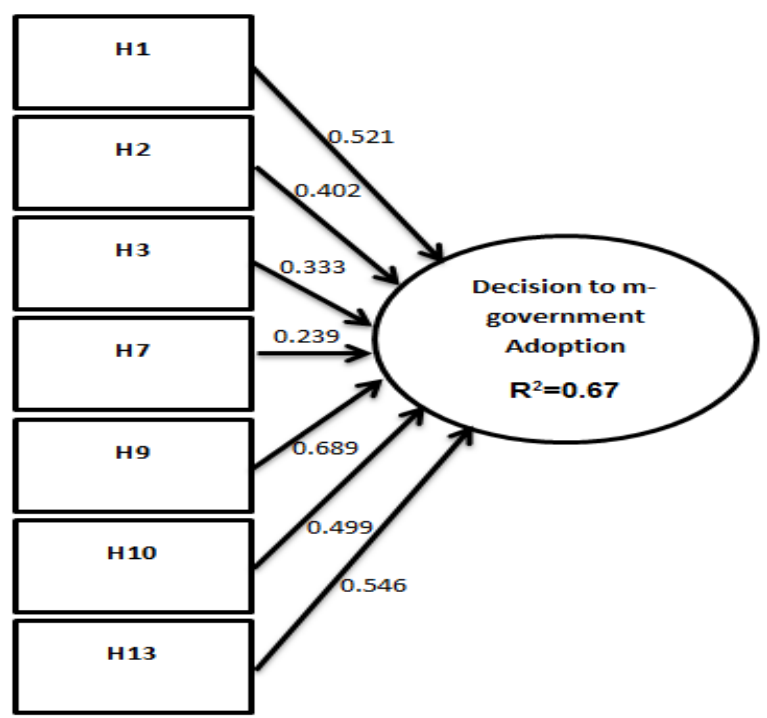

Figure 2: Research Model with a summary of the factors with a positive impact on the decision to adopt mgovernment services

\section{Conclusions}

This research addressed the factors affecting the citizens in the adoption of m-government services in a country experiencing rapid development, namely Jordan. The findings of this research showed that privacy, trust, efficiency in time and distance, ease of use, value for money and mobile infrastructure robustness have a significant impact on the citizens to adopt $\mathrm{m}$ government services in Jordan. Privacy assurance can affect in increasing the number of users of SMS-based e-government services, and hence the adoption of m-government [31]. This research concluded that there is a strong correlation between trust in SMS technology and willingness of the citizens to adopt m-government services. Accordingly, the Jordanian government can promote this trust by factors such as improving public service value for money policies, create and maintain robust mobile network infrastructure. This research also contributed to the development of the efficiency metrics for the delivery of m-government services in Jordan. These are represented by the speed of service (response time), cost of access to the service and finally ease of use for this type of services. All of these recommendations, if they were taken into consideration lead to the empowerment of citizens to catch up with the mobile and wireless technologies, and use them in their lives and daily dealings, including government transactions. Jordan is still in its infancy in this area and therefore this research is one of the very few published in this context. However, future research could focus on the collection of a large number of responses from different areas not covered in this research on the one hand, and on the other hand prioritize factors, in terms of their importance to the citizen in order to draw the plans and policies that ensure application optimized for this kind of services.

\section{ACKNOWLEDGEMENTS}

The authors are grateful to the Applied Science Private University, Amman, Jordan, for the financial support granted to cover the publication fee of this research article. 
International Journal of Computer Science \& Information Technology (IJCSIT) Vol 8, No 4, August 2016

\section{REFERENCES}

[1] Abanumy, Abdulmohsen, And Pam Mayhew. "M-Government Implications For E-Government In Developing Countries: The Case Of Saudi Arabia." Euro Mgov.Vol. 2005. 2005.

[2] Kailasam, Rameesh. "M-Governance... Leveraging Mobile Technology To Extend The Reach Of EGovernance." Proceedings Of The Trai Conference On Mobile Applications For Inclusive Growth And Sustainable Development. 2010.

[3] Al-Huan, Omar. "Toward The Utilization Of M-Government Services In Developing Countries: A Qualitative Investigation." International Journal Of Business And Social Science 3.5 (2012).

[4] Zamfiroiu, Alin, Vali Rădut, And Carmen Rotună. "Mobile Interaction In An M-Government System." Journal Of Advanced Distributed Learning Technology 2.5 (2014): 51-61. [5] Ashis Kumar Mahapatra, Sukanta Kumar Sahu, "Challenge Of Wireless And Mobile Tecnologies In Government", Available Online At: Http://Www.Iceg.Net/2008/Books/2/33-303-311.Pdf

[6] Alhussain, T. And Drew, S. "Towards Secure M-Government Applications: A Survey Study In The Kingdom Of Saudi Arabia. In International Conference On Intelligent Network And Computing (Icinc 2010). Ieee

[7] Oghuma, Apollos Patricks, Myeong-Cheol Park, And Jae Jeung Rho. "Adoption Of Mgovernment Service Initiative In Developing Countries: A Citizen-Centric Public Service Delivery Perspective." 19th Its Biennial Conference, Bangkok 2012: Moving Forward With Future Technologies-Opening A Platform For All. No. 72510.International Telecommunications Society (Its), 2012.

[8] Al-Khamayseh, Shadi, And Elaine Lawrence. "Towards Citizen Centric Mobile Government Services: A Roadmap." Collecter Europe 2006129 (2006).

[9] Oui-Suk, Uhm. "Introduction Of M. Government \& It Convergence Technology." Kaist Institute For It Convergence (2010).

[10] Al-Hadidi, Ahmed, And Yacinerezgui. "Adoption And Diffusion Of M-Government: Challenges And Future Directions For Research." Working Conference On Virtual Enterprises.Springer Berlin Heidelberg, 2010.

[11] Olanrewaju, Oyenike Mary. "Mobile Government Framework-A Step Towards Implementation Of Mobile Government In Nigeria." International Journal Of Information Science 3.4 (2013): 89-99.

[12] Weerakkody, Vishanth, Et Al. "E-Government Implementation In Zambia: Contributing Factors." Electronic Government, An International Journal 4.4 (2007): 484-508.

[13] Susanto, Tony Dwi, And Robert Goodwin. "Factors Influencing Citizen Adoption Of Sms-Based Egovernment Services." Electronic Journal Of E-Government 8.1 (2010): 55-71.

[14] Van Greunen, Darelle, And Fiona Wilson."User Requirements For Mobile Government In The Western Cape." 2013 Conference. 2013.

[15] Kushchu, Ibrahim, And Halidkuscu. "From E-Government To M-Government: Facing The Inevitable." The 3rd European Conference On E-Government. Mcil Trinity College Dublin Ireland, 2003.

[16] Sareen, Mamta, And L. Chanana. "Exploring Factors Affecting Use Of Mobile Government Services In India." Problems And Perspectives In Management11.4 (2013): 86-93.

[17] Zefferer, Thomas. "Mobile Government: E-Government For Mobile Societies."Stocktaking Of Current Trends And Initiatives. Vienna: Secure Information Technology Center. Retrieved December 15 (2011): 2011

[18] Accenture, 2014 Accenture, "Digital Government. Pathways To Delivering Public Services For The Future. A Comparative Study Of Digital Government Performance Across 10 Countries", Http://Nstore.Accenture.Com/Acn_Com/Accenture-Digital-Government-Pathways-To-Delivering Public-Services-For-The-Future.Pdf. 2014.

[19] Assar, "M-Government In Saudi Arabia", International Journal Of Computer Science And Software Engineering, January 2015.

[20] Maranny, E. A. "Stage Maturity Model Of M-Government (Smm M-Gov): Improving EGovernment Performance By Utilizing M-Government Features". University Of Twente: The Netherlands, 2011 
International Journal of Computer Science \& Information Technology (IJCSIT) Vol 8, No 4, August 2016

[21] Appolis, Kurt, Et Al. "Availability And Adoption Of M-Government Services In South Africa." 2012 Conference. 2012.

[22] Alsenaidy, A., And T. A. U. S. E. E. F. Ahmad. "A Review Of Current State M-Government In Saudi Arabia." Global Engineers \& Technologists Review 2.5 (2012): 5-8.

[23] Zamfiroiu, Alin, Vali Rădut, And Carmen Rotună. "Mobile Interaction In An M-Government System." Journal Of Advanced Distributed Learning Technology 2.5 (2014): 51-61.

[24] Naqvi, Syed Jafar, And Hafedh Al-Shihi. "M-Government Services Initiatives In Oman." Issues In Informing Science And Information Technology 6.2 (2009): 817-824.

[25] Wang, Changlin, Et Al. "Model For Value Creation In Mobile Government: An Integrated Theory Perspective." International Journal Of Advancements In Computing Technology 4.2 (2012).

[26] Liu, Yong, Et Al. "An Empirical Investigation Of Mobile Government Adoption In Rural China: A Case Study In Zhejiang Province." Government Information Quarterly 31.3 (2014): 432-442.

[27] Chete, F. O., Et Al. "Citizens' Adoption Of Sms Based E-Government Services In Lagos State, Nigeria." The Pacific Journal Of Science And Technology 13.2 (2012).

[28] Abdelghaffar, Hany, And Yousramagdy. "The Adoption Of Mobile Government Services In Developing Countries: The Case Of Egypt." International Journal Of Information 2.4 (2012): 333341.

[29] Basamh, Saeed Saleem, Hani A. Qudaih, And Mohd Adam Suhaimi. "E-Government Implementation In The Kingdom Of Saudi Arabia: An Exploratory Study On Current Practices, Obstacles And Challenges." International Journal Of Humanities And Social Science 4.2 (2014): 296-300.

[30] Alomari, Mohammad A., And Hamzah H. Elrehail. "Mobile-Government: Challenges And Opportunities Jordan As Case Study." International Journal Of Business And Social Science 4.12 (2013).

[31] Althunibat, Ahmad, Thamer A. Alrawashdeh, And Mohammad Muhairat. "The Acceptance Of Using M-Government Services In Jordan." Information Technology: New Generations (Itng), 2014 11th International Conference On. Ieee, 2014.

[32] Altarwneh, Mohammad, And Haroon Altarawneh. "The State Of Using Sms-Based E-Government Services: Case Study In Jordan." International Journal Of Advanced Networking And Applications 4.3 (2012): 1591.

[33] Susanto, Tony Dwi. "Individual Acceptance Of Sms-Based Services." International Journal Of Information Systems And Engineering 1.1 (2015): 1-11

[34] Hair, Joseph F. "Multivariate Data Analysis." (2009).

[35] Http://Www.Moict.Gov.Jo

\section{AUTHORS}

Yousef Elsheikh is an assistant professor of Information Technology at the Applied Science University. He holds PhD in Informatics from University of Bradford, UK and MSc in Information Technology from University of the West of England, UK. He is currently working as a head of the Computer Information Systems department at the Applies Science University. His research interests includes conceptual modelling, e-

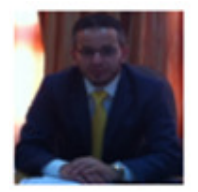
business applications, information systems engineering, knowledge based representations, Ontologies and issues in software engineering.

Mohammad Hijjawi is currently an assistant professor at the Applied Science University in Amman, Jordan. Dr.Hijjawi holds a Ph.D. degree in Computer Science from Manchester Metropolitan University, UK. His research interests include: Conversational Agents, machine learning, Data Mining and Arabic language processing.

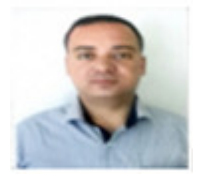

